\title{
Problems and prospects of development of intermediary business in Ukraine
}

\author{
Olena Gromova ${ }^{1}$, Alla Derhousova ${ }^{1}$, Tetiana Glushenko ${ }^{1}$, and Daria Biletska ${ }^{1 *}$ \\ ${ }^{1}$ Ukrainian State University of Railway Transport, Management and Administration Department, \\ Feuerbach sq., 7, Kharkiv, 61050, Ukraine
}

\begin{abstract}
The article deals with the problem of identification and search of the future-oriented directions of intermediary business development in Ukraine in the conditions of transformation processes in the national economy. The article describes the essence of trade and intermediary activity, outlines the main components and represents the content of trade and intermediary transactions. On the basis of the general analysis of theoretical and practical works on the implementation of trade and intermediary activities, the main problems that impede the development of intermediary business in Ukraine are identified. It is noted that it is expedient to use the formulated signs and principles for the organization of trade and intermediary activities. The prospects of using the newest marketing tools (neuromarketing) in the trade-intermediary business are described. It is noted that it is necessary to improve the normative base, that now inhibits the development of trade and intermediary activities.
\end{abstract}

\section{Problem statement}

The economic stability of the organization, its survival and the effectiveness of its activities in the context of market relations are inextricably linked with its continuous improvement and development. At the same time, the organization's improvement should be based on the principle of adaptation to a changing environment.

This is especially true for enterprises operating in the trade and intermediary sector, which currently form an integral part of business and trade activities of the infrastructure entities in the product market. Therefore, the problem of identifying problems and looking for promising directions for the development of intermediaries in Ukraine are of particular relevance.

\section{Analysis of research and publications}

Issues of development of the mediation business are studied in the works of both domestic and foreign scientists. Among them are the works of Gaponchuk N.V., Gerchikova I.N., Didkovsky M.I., Dunskaya A.R., Tokmin L.N. and others.

\footnotetext{
*Corresponding author: d.beletskaya2015@ukr.net
} 
Among the works devoted mainly to the foreign economic activity of the enterprise, scientists mostly study issues of the organization of intermediaries' work in the implementation of foreign economic activity of the enterprise.

Most sources compare the content of trade and intermediary activities with the essence of the concept of "trade" and pay more attention to the fact that it is an initiative, independent activity for profit. But this interpretation does not cover the broader nature of the activity, since its meaning reduces to the primitive processes of buying and selling.

\section{Presentation of the main research}

Sales transactions are a significant part of the trade and intermediary activity, and its content, as it has already been noted, is wider. This can be explained by the fact that trade mediation involves a large amount of work in the interests of the manufacturer, such as search for contractors for the sale of goods, preparation and execution of the transaction, lending for the parties, provision of guarantees for the sale of goods and receiving of appropriate means by the seller, insurance of goods and risks during transportation, carrying out promotional activities for the promotion of products to markets, provision of organizational, commercial, consulting and other services.

As a result, we can formulate the essence of the concept of "trade and mediation".

In general, trade and intermediary transactions refer to transactions involving the purchase and sale of goods, that are performed on behalf of the supplier (manufacturer or exporter / importer) by an independent commercial agent.

Such activities as procurement, distribution and sales also relate to the trade and intermediary activities, as shown by the study of world experience.

However, companies that perform these operations remain in an independent status. They do not act as producers or final customer, but are in the sales circle and carry out any transaction with the product at their own discretion. For the most part, they are engaged in commerce, while large intermediaries can sometimes perform production operations, mainly related to the processing of procured and sold goods, transportation, insurance, warehousing of goods, but these functions are subject to commercial operations.

Marketing activities and trade intermediation services are very closely linked. It is characterized by a modern marketing concept that is followed in most markets. Using the marketing toolkit, the staff of the company (both employees and managers) receives information about consumer wishes, pricing and purchasing power, the willingness to pay exactly this price, and in which specific regions the demand for certain products is higher, and therefore the sale of products can provide maximum profits.

Marketing allows you to determine which types of production are most promising for investing or establishing a new business. Marketing research also helps determine the direction of the organization of the sales process and how to build an advertising strategy. Marketing calculations make it possible to compare several variants of enterprise development on the efficiency of production and sales costs; determine which types of goods are sold to a particular consumer in a particular region, and which will subsequently bring the greatest return on each investment unit. Today, most intermediary companies are trying to enter the external market, starting to operate in a new economic environment, where market relations have reached a higher level of development.

However, if an enterprise does not follow and does not master advanced marketing methods, it will eventually become noncompetitive. Knowledge of marketing principles makes it possible to arrange work with the consumer, critically evaluate the company's potential and monitor competitors, and choose the right market segment and economic activity. Flexibility of intermediary activity should be manifested primarily in the operational account of market requirements. 
For this purpose, a lot of attention and time should be devoted to the study and forecasting of commodity markets, the development of a sales advertising campaign, as well as the attraction of innovations in trade and intermediary activities, and, if necessary, to adjust the profile of activities, to make changes in organizational structures of commerce.

In the modern world, we have been witnessing the emersion of neuromarketing, which allows you to understand the consumer's response to marketing irritants better and to improve the effectiveness of marketing methods by studying the brain's response. Therefore, this aspect should be particularly focused on, especially when creating a trade and intermediary network and forming communication links.

The research of scientific and practical works has proved that trade and intermediary activities in conditions of essential market relations should be determined by the following features:

1. Motives and conditions of origin - the result of the objective laws of commodity production and circulation, the formation of real needs of economic entities.

2. The role and place of mediation - an organic part of the distribution and distribution system, which effectively promotes the promotion of goods from the manufacturer to the consumer.

3. Subject of trade mediation - any product is intended for professional use or resale.

4. Economic guarantees - the intermediary entrepreneur shares the risk with the manufacturers of goods related to the impossibility of ale or selling at prices that do not provide the necessary level of profit.

5. The main objectives of the intermediary - the intermediary operates in the interests of its counterparties and in their own interests in order to receive the corresponding profit. goods.

6. Legal attitude to the subject of mediation - mediators mainly acquire the right to own

7. Organizational conditions of operation - variety and flexibility of organizational forms of mediation, types of works and services.

8. The measure of freedom and the scope of activity is a free and appropriate specialization in the segment of the market where a qualifying advantage can be obtained.

9. Methods and techniques of work with consumers - a differentiated approach to various needs, focusing on immediate consumer's demands, carried out on the basis of market research in the segmented market.

10. Source of income - payment determined by socially necessary expenses for the implementation of these works within the wholesale price of the producer and the price of demand.

11. Payment of labor - based on the results of the activity and the real contribution of each employee.

Effective trading and intermediary activities should be based on a number of principles:

1. Increasing the role of strategic planning and management to ensure stable production and consumption of products in the national economy, creating conditions on this basis for a more stable and reliable functioning of the sphere of circulation.

2. Allocation of economic priorities in stimulation of material and financial flows in the most effective branches, based on economic-political and social problems, which are solved by the country at each stage.

3. Global mobilization of internal reserves, ensuring rational use and economics of financial and material resources in each link of the national economic complex.

4. Increase of responsibility for fulfillment of contractual obligations on deliveries and transportation of products by all participants of market turnover on the basis of mutual rights and obligations, stipulated by economic contracts, treaties, orders.

5. The most effective organization of the process of sales of products manufactured by enterprises, and procurement of material resources by consumers in the required range and 
in the form prepared for industrial consumption at a minimum cost of treatment and aggregate stocks.

6. Creation of economic conditions and the use of marketing tools allow mediators to meet the demands of customers in a qualitative and efficient manner, flexibly maneuver with material resources and accelerate their reversibility in favor of stabilization and economic growth.

7. Creation of a modern highly equipped technical material base with key elements of the market infrastructure in the commercial chain, its continuous improvement for the proportional development of the sphere of circulation in accordance with the requirements of the sphere of production.

8. Use of scientific methods of management of material flows on the basis of modern logistic approaches and methods, wide use of opportunities of the electronic market, the Internet system in order to maximize and timely satisfaction of market requests of buyers.

9. Use of forms and methods of social and ethical marketing to establish mechanisms of mutually beneficial agreements not only with market partners, but also in society through the active use of communicative models, in particular public relations.

During trading and intermediary activities, participants face certain issues.

The most difficult one is the legislative framework, because it is weak and outdated.

It should be noted that the legal basis for regulation of trade and intermediary activities, as well as all economic turnover, consists of fragments of indirect laws.

Its basis consists of departmental regulations, instructions and regulations, and most often the development of the intermediaries themselves. Of course, such a base cannot be considered acceptable.

Another reason that slows progress in the area of development of trade and intermediary activities is organizational. The content of the problem is that in Ukraine organizational forms of trade mediation are not formed under control. For the most part, they have the appearance of somewhere else altered copies of foreign structures, which are important to adapt to the realities of national reality.

In the course of the study, it is proved that the structure of intermediary firms tends to simplify and is ineffective in functional terms. First of all it concerns exchanges, auctions, distributor, consignment firms, brokerage offices. They have a limited functional structure, but at the same time it is universal. This can be explained by two reasons: firstly, an attempt to reduce the cost of the operation of a brokerage firm; and secondly, the desire to universalize the activities of intermediaries.

There is a need to develop new, optimal organizational forms taking into account international experience and features of the domestic economy in the field of trade mediation.

The current issue is the territorial organization of intermediaries, their specialization. The reason is that a very important principle of the operation of most intermediaries is the division of territories. This means that the intermediary is territorially limited in its activities. The implementation of this principle requires the regulation of the territorial organization of intermediaries, their demarcation, specialization, revision of antimonopoly legislation.

The problem with personnel is an important issue to be addressed when it comes to organizing trade mediation.

Resellers carry out large-scale internal and external transactions, complex in commercial, financial and legal terms. But for some reason, they lack the qualifications.

In addition, higher education institutions in Ukraine do not train personnel for trade and intermediary activities.

In this regard, it is advisable to introduce the specialty "Trade and mediation" in colleges, trade and economic institutions of higher education in the country. Compliance 
with the principles of forming commercial relations will allow the trade and intermediary system to actively influence production, to identify discrepancies between supply and demand for certain types of goods and services, to form rational commercial relations between suppliers and consumers.

Multiple transactions in international trade are carried out with the help of intermediaries - individuals, organizations, etc., which have an intermediate position between producers and end users. From the economic point of view, it is entirely possible for them to apply the term "resellers", which is more common in international commercial matters.

The majority of commodity groups of machinery and equipment, raw materials, trade products, foodstuffs, consumer goods and basic semi-finished products are sold via resellers.

The feature of the modern business environment is that most of the international trade turnover is carried out with the participation of intermediaries. We mean trade and intermediary firms, organizations and individuals.

The importance of intermediaries is inherent both for the trade in mass demand and for trade in products for which demand is very limited due to their specific characteristics.

Without intermediaries, the sale of exclusive goods is not rarely done, in the event that there is only one monopoly producer and 2-3 end-users in the world market.

Companies use intermediaries to improve the efficiency and economic feasibility of foreign economic operations.

The economic efficiency of transactions performed by intermediaries, even taking into account the costs of remuneration, increases due to the following aspects:

- the involvement of intermediaries increases the speed of sales of goods, which leads to an increase in sales revenue due to accelerated capital turnover;

- intermediaries, more responsive to changing market conditions that allows you to sell goods on more favorable terms for the exporter;

- the involvement of intermediaries provides an opportunity to increase the competitiveness of goods at the expense of shorter delivery times and intermediate warehouses, better warehousing and storage of goods, pre-sale service and maintenance, special marking, additional equipment of products in the country of sale in accordance with local requirements;

- taking advantage of lending on various terms, some intermediaries finance exporters' transactions, invest their own capital in the creation and operation of a sales network, which gives the opportunity to benefit from the saving of money invested;

- intermediaries provide optimization of communication costs, accounting savings, help reduce credit risks, facilitate faster access to new markets;

- intermediaries are the source of valuable primary information about segmentation and market capacity, demand dynamics, margins of product price fluctuations, state of competitors, requirements for the quality of goods.

After analyzing the activity of international trade, we can conclude that, first and foremost, medium and small enterprises are turning to the resellers in the sphere of foreign trade in particular.

The involvement of a mediation tool is central to the marketing of their products. But large-scale industrial companies, including multinationals, are turning to independent intermediaries. Transnational corporations, meanwhile, involve intermediaries mainly for the implementation of secondary products, in some new or complex markets, in smallcapacity markets, in the absence of their own sales network based on trade subsidiaries and representative offices, with relatively small volumes or with the occasional conclusion of an export-import operations. 
In determining the importance of intermediaries, it should be noted that they have become virtually indispensable tools for the use of certain specific forms of sales by an exporter or importer, for example, stock trading, participation in international tenders for machinery, equipment and capital construction, patents trading and licenses. Referring to the involvement of intermediaries, it is necessary to remember the objective shortcomings, which entail the attraction of the trade and intermediary level to the sale of goods. The lack of a direct contact with the sales market is one of them.

Thus, when considering the issue of engaging a reseller, the manufacturer must clearly calculate and understand the economic efficiency of his activities.

In the event that the intermediary is not able to provide additional income compared with what the manufacturer receives in the case of self-distribution of goods on the market, its attraction is not economically meaningful.

Unfortunately, a thorough calculation of the possible economic effect of using an intermediary in practice is very difficult. It is impossible to estimate, for example, the lost profit from the use of an intermediary, which the manufacturer does not even suspect because of his ignorance.

\section{Conclusion}

Nowadays, Ukraine has no clear strategy for the development of intermediary business. Having pointed out the main shortcomings, we can state that now, in order to improve the activities of intermediaries in Ukraine as a whole, it is necessary first of all to pay attention to improving the legislative framework, to start actively using modern marketing tools (neuromarketing) and to pay attention to the training of specialized staff. Only a comprehensive approach will enable an accelerated development of intermediary business in Ukraine and increase the competitiveness of the country in the world market.

\section{References}

1. M. I. Belyavtsev, Commodity market infrastructure, 43-50 (2015)

2. N. Gaponchuk, Problems of the Sustainable Development of National Economies, 7375 (2013)

3. I. Gerchikova, Management [3rd ed.] (1997)

4. I. Gerchikova, International Commercial Business [2nd ed.] (2001)

5. M. I. Didkivskyj, Foreign economic activity of the enterprise (2006)

6. A. R. Dunska, Economic Newsletter of NTU "KhPI", 9, 89-95 (2012) 